\title{
VISÕES DO ORIENTE E DOS IMPÉRIOS; THÉOPHILE GAUTIER E GIUSEPPE VERDI.
}

\section{VIEWS OF THE EAST AND OF EMPIRES: THÉOPHILE GAUTIER AND GIUSEPPE VERDI.}

Celina Maria Moreira de MELLO ${ }^{1}$

\begin{abstract}
RESUMO: A ópera Aida (1871), do compositor italiano Giuseppe Verdi (1813-1901), explora um tema pitoresco exótico, a força, a selvageria e a plasticidade dos antigos impérios egípcios, que tanto marcaram as imagens do outro no século XIX e que também podemos encontrar em inúmeras obras românticas, tais como o Romance da múmia (1857) de Théophile Gautier (1811-1872). 0 poeta e romancista francês compartilhou com o compositor um imaginário romântico que fez do Egito um dos espaços mais evocados no século XIX, para uma ambientação pitoresca oriental. Ambos projetam as imagens românticas do antigo Egito que encantaram tantos viajantes e cuja plasticidade muito deve às imagens que foram se formando, a partir de um fundo de textos, documentos, desenhos, interpretações e fabulações criadas por poetas, escritores e pintores. Sua consolidação resulta de processos de dominação política e de representação, em que a literatura e a arte têm um papel primordial. Evocamos, aqui, de que modo os antigos impérios do Egito são reconstruídos por Théophile Gautier em Le Roman de la momie e por Verdi em Aida, na mesma lógica das relações entre a arte e a sociedade.
\end{abstract}

\footnotetext{
${ }^{1}$ Professora Titular de Língua e Literatura francesa da Universidade Federal do Rio de Janeiro, Bolsista de Produtividade em Pesquisa do CNPq.
} 
PALAVRAS-CHAVE: criação poética; romantismo; imagens do oriente; Théophile Gautier; Verdi.

ABSTRACT: The opera Aida (1871), by Italian composer Giuseppe Verdi (1813-1901), explores a picturesque and exotic theme: the power, savagery and plasticity of the Ancient Egyptian empires, which marked nineteenth-century images of otherness that can also be found in many romantic works, such as Le Roman de la momie (1857), by Théophile Gautier (1811-1872). The French poet and novelist shared a romantic ideal with the Italian composer that turned Egypt into the most evoked space for an eastern picturesque ambience. Both artists project romantic images of ancient Egypt which enchanted travellers and whose plasticity derived from texts, documents, drawings, interpretations and confabulations created by poets, writers and painters. The consolidation of such images results from processes of political and representational domination, in which art and literature played a key role. In this essay we show how the ancient empires of Egypt were reconstructed by Théophile Gautier in Le Roman de la momie and by Verdi in Aida, under the same logic that governs the relationship between art and society.

KEYWORDS: poetic creation; romaticism; eastern images; Théophile Gautier; Verdi.

Em abril de 2013, na temporada de ópera do Teatro Municipal do Rio de Janeiro, houve cinco récitas da ópera Aida, do compositor italiano Giuseppe Verdi (1813-1901), com inegável sucesso de público. ${ }^{2}$ A ópera de Verdi explora um tema pitoresco exótico, a força, a selvageria e a plasticidade dos antigos impérios egípcios, que tanto marcaram os imaginários do outro no século XIX e que também podemos encontrar em inúmeras obras românticas, tais como o Romance da múmia (1857) de Théophile Gautier (18111872). Romantismo não indicará, aqui, um estilo de época, tal como é definido nos manuais de literatura, e cujos limites temporais são os de uma geração, mas uma formação discursiva moderna,

\footnotetext{
${ }^{2}$ As récitas se realizaram nos dias 20 e 26 de abril às $20 \mathrm{~h}, 23$ e 28 de abril e $1^{\circ}$. de maio às 17.00 com a direção musical e regência de Isaac Karabtchevsky, a Orquestra Sinfônica e o Coro do Teatro Municipal.
} 
um recorte tributário da arqueologia foucaultiana que contempla períodos da história mais extensos, definidos pelo conceito de longa duração da nova história.

Cabe lembrar, na esteira do ensaio de Edward Saïd, O orientalismo (2007), que o Oriente, em um contexto histórico europeu colonial, é uma construção, em que se confundem épocas e culturas diversas, que vão do Marrocos ao Japão. A consolidação ocidental desta imagem de oriente, com sua face oculta, a de um ocidente civilizado e hegemônico, resulta de processos de dominação política e de representação internalizada em forma de habitus ${ }^{3}$, em que a literatura e a arte têm um papel primordial. Sua plasticidade, que se quer icônica de um esplendor passado, muito deve às imagens que, ao longo dos séculos, foram se formando, graças a um fundo de textos, documentos, desenhos, interpretações e fabulações que devemos aos viajantes, arqueólogos e historiadores, e também a cronistas, poetas, escritores e pintores.

Os costumes e a plasticidade dos antigos impérios do Egito são reconstruídos por Théophile Gautier em Le Roman de la momie (1857) e por Verdi em Aida (1871), com uma inspiração poética associada a um grande cuidado de documentação. Não se trata, contudo, de relatos de viajantes, nem de obra de historiador, e muito menos de ciência política: Gautier e Verdi compartilharam, com muitos de seus contemporâneos, e suas obras contribuíram para formar, um imaginário romântico que fez do Egito dos faraós um dos espaços mais evocados, pelos escritores e artistas do século XIX, para uma ambientação pitoresca oriental. Por outro lado, tanto o romance quanto a ópera não podem ser cortados de seu contexto político, da marcante presença dos franceses no Egito, repercutindo a campanha de Napoleão (1798-1799), no Egito, ou de episódios que são um símbolo das relações entre

\footnotetext{
${ }^{3}$ Um dos conceitos fundamentais da teoria dos campos de Pierre Bourdieu: "système de dispositions durables acquis par l'individu au cours du processus de socialisation qui génère et organise les pratiques et les représentations des individus et des groupes. " - "sistema de disposições duráveis adquiridas pelo indivíduo ao longo do processo de socialização que gera e organiza as práticas e as representações dos indivíduos e dos grupos." (BONNEWITZ, 2002, p. 94, tradução nossa)
} 
europeus e egípcios, como a construção do canal de Suez, que vai de 1859 a 1869.

0 romance de Gautier e a ópera de Verdi inserem-se neste acervo de imagens compõem um imaginário do Oriente e do Egito, que por sua vez suas criações vieram enriquecer. 0 escritor e o compositor se inspiram de um Egito que foi em grande parte redescoberto, no século XIX, desenhado, repertoriado, classificado, representado, interpretado e valorizado como um patrimônio da humanidade, por viajantes, artistas e arqueólogos ocidentais, em que dois grandes nomes são franceses: Jean-François Champollion (17901832) e Auguste Mariette (1821-1881). Entre os viajantes ilustres que se interessaram pelas grandes descobertas arqueológicas que lá foram realizadas no século XIX, encontramos o Imperador Pedro II, que fez duas viagens ao Egito, em 1871 e 1876, quando visitou o Alto Egito em companhia precisamente de Auguste Mariette.

\section{Théophile Gautier e o Romance da múmia}

O Egito antigo é um tema recorrente entre os autores do romantismo e igualmente presente na obra de Théophile Gautier, desde seu primeiro texto Un repas au désert de l'Egypte (Uma refeição no deserto do Egito, 1831). Há também dois contos, Une nuit de Cléopâtre (Uma noite de Cleópatra, 1838) e Le pied de Momie (O pé da múmia, 1840) (GAUTIER, 1990); destaca-se o dueto de poemas " Nostalgies d'obélisques », publicado no jornal La Presse, em 4 de agosto de 1851 (GAUTIER, 1968, p70). Curiosamente, até a inauguração do Canal de Suez, em 1869, Théophile Gautier não tinha nenhum conhecimento direto do Egito. 0 país, para ele, fazia parte desse oriente imaginário, que fascinou várias gerações e que ele contribuiu para fascinar.

Flaubert e seu amigo Maxime Du Camp, este em missão arqueológica oficial, partem para o Egito em 1849, país que visitaram ao longo de oito meses, indo até o Alto Egito, e de que retornaram, 
como ainda hoje voltam os viajantes, carregados de fotos - as de Maxime du Camp ${ }^{4}$, claro, pois Flaubert detestava fotografias - de sensações e experiências. A estreita amizade de Théo com Gustave Flaubert e Maxime Du Camp, nos anos 1850, aproxima-o ainda mais de um Egito antigo, que já o havia inspirado e com que sempre sonhara: uma breve carta de Maxime du Camp a Théophile Gautier, datada de 31 de março de 1850, estaria na origem dos poemas dos obeliscos.

A Luxor, ô Théo, j’ai beaucoup pensé à vous, et voici pourquoi. - Parce qu'il y a un obélisque! - Cela peut vous sembler étrange [...] et cependant c'est l'obélisque qui m'a fait songer à vous. - [...] Depuis qu'ils sont séparés, ces deux siamois monolithes s'embêtent de façon désespérante. Celui qui est à Luxor envie le destin de son frère. Celui de Paris est encore plus triste et se désespère en pensant au pays [...]. Cher maître j'ai vu là un beau sujet de vers. ${ }^{5}$

$O$ romance da múmia trata de um tema que corresponde ao enorme interesse dos franceses pelo Egito antigo, que é despertado, sobretudo, pela missão civilizadora de Napoleão e a descoberta de Champollion, o qual, ao decifrar a pedra de Roseta, permitiu a leitura dos hieróglifos, até então indecifráveis. A possibilidade de ler os registros em hieróglifos revoluciona a reconstituição da história antiga do Egito, ao descortinar episódios fabulosos das diversas dinastias dos faraós, que haviam sido conservados em registros

\footnotetext{
${ }^{4}$ Maxime Du Camp, que aprendera a tirar fotos especialmente para esta viagem, publica, em 1852, um livro que resulta desta viagem: Égypte, Nubie, Palestine et Syrie : dessins photographiques recueillis pendant les années 1849, 1850 et 1851, accompagnés d'un texte explicatif et précédés d'une introduction par Maxime Du Camp, chargé d'une mission archéologique en Orient par le ministère de l'Instruction publique, Paris, Gide et Baudry, 1852.

5 "Em Luxor, ó Théo, lembrei muito de você, e eis o motivo. - Porque há um obelisco! Isto poderá lhe parecer estranho [...] e contudo foi por causa do obelisco que lembrei de você . - [...] Desde que foram separados, estes dois monolitos siameses entendiam-se de um modo desesperador. - Aquele que se encontra em Luxor inveja o destino do irmão. Aquele que está em Paris está ainda mais triste e fica desesperado ao lembrar de sua terra [...]. Caro poeta, pensei que seria um belo tema para um poema." (Lov. C 493, ff. 430-431 apud GAUTIER, 1968, p. 70, tradução nossa).
} 
de papiro ou nas paredes de templos e túmulos, destruindo, definitivamente, a secular datação do mundo bíblico, adotada pela Igreja Católica. 0 grand tour ${ }^{6}$ se expande, e a arqueologia naquelas terras bíblicas torna-se uma paixão. Novos temas aparecem na pintura, na literatura e na música, permitindo que se alargue o universo da erudição e do mundo antigo.

O romance da múmia foi publicado, em sua primeira versão, em 1857, no formato de folhetim, no Moniteur Universel, de 11 de março a 6 de maio (LOVENJOUL, 1887, p. 125), e depois, em 1858, em formato de livro, pela editora Hachette. ${ }^{7}$ É dedicado a Ernest Feydeau, autor da Histoire des usages funèbres et des sépultures des peuples anciens (História dos usos fúnebres e das sepulturas dos povos antigos), livro publicado em 1856, que teria sido o inspirador deste romance. 0 historiador teria colocado à disposição de Gautier a documentação necessária para sua fidelidade à história e aos costumes do Egito antigo, conforme fica registrado na dedicatória:

A M. Ernest Feydeau. Je vous dédie ce livre, qui vous revient de droit ; en m'ouvrant votre érudition et votre bibliothèque, vous m'avez fait croire que j'étais savant et que je connaissais assez l'Egypte antique pour la décrire ; sur vos pas, je me suis promené dans les temples, dans les palais, dans les hypogées, dans la cité vivante et dans la cité morte; vous avez soulevé devant moi le voile de la mystérieuse Isis et ressuscité une gigantesque civilisation disparue. L'histoire est de vous, le roman est de moi ; je n'ai eu qu'à réunir par mon style, comme par un ciment

\footnotetext{
${ }^{6}$ Nos séculos XVII, XVIII e XIX, longa viagem pela Europa, sobretudo Itália e Grécia que vem complementar a educação de jovens rapazes burgueses. Esta viagem, que é a origem do turismo, está voltada para visitas a sítios arqueológicos, igrejas, palácios e ateliês de artistas, e também bailes, tavernas e lupanares.

${ }^{7}$ Lovenjoul registra: "Voici une curieuse dédicace inédite d'un exemplaire de la première édition de cet ouvrage (Hachette, 1858). Je dédie ce roman pharmaceutique et ganaliforme à l'embaumeur F. Silas, mon ami insulaire et bientôt continental. Théophile Gautier. Londres, Panton-square, 9 juin 1862." - "Eis um curioso autógrafo inédito de um exemplar da primeira edição desta obra (Hachette, 1858). Dedico este romance farmacêutico e ganaliforme ao embalsamador F. Silas, meu amigo insular e em breve continental. Théophile Gautier. Londres. Panton-square, 9 de junho de 1862." (LOVENJOUL, 1968, p. 127, tradução nossa) Disponível em http:// gallica.bnf.fr/ark:/12148/bpt6k8840n. Acesso em 05 de novembro 2014.
} 
de mosaïque, les pierres précieuses que vous m'apportiez. Th. G. ${ }^{8}$

Neste romance, sonhos, devaneios e visões noturnas reatualizam elementos próximos do que Gautier chamava de fantasias, ou seja, narrativas fantásticas; mas, graças a este respeito documental, a obra foi recebida como um romance histórico. Gautier, sempre fiel a seus fantasmas, faz da ambientação dos ritos funerários egípcios o tema perfeito para representar o desafio que se coloca à narrativa literária. Em suas descrições ele joga com simulacros pelos quais o leitor se apaixona, do mesmo modo que o jovem Lorde Evandale se apaixona pela múmia do título, Tahoser. Filha do grande sacerdote, ela é desenterrada pelos europeus de um túmulo até então inviolado: "Une tombe que n'auront fouillée ni les rois pasteurs, ni les Mèdes de Cambyse, ni les Grecs, ni les Romains, ni les Arabes, et qui nous livre ses richesses intactes et son mystère vierge [...]. »9.

Ao penetrar no túmulo, o jovem inglês tem a impressão de que havia voltado no tempo e que a história se anulara projetando-o em um passado que se torna seu presente: "Une main invisible avait retourné le sabier de l'éternité, et les siècles, tombés grain à grain comme des heures dans la solitude et la nuit, recommençaient leur chute.." ${ }^{10}$ A "mão invisível" é aquela do autor e seu gesto representa

\footnotetext{
8 "Ao Senhor Ernest Feydeau. Eu lhe dedico este livro, que é seu por direito; ao me abrir sua erudição e sua biblioteca, o senhor me levou a crer que eu era um erudito e conhecia suficientemente o Egito para o descrever; seguindo seus passos, andei pelos templos, palácios, hipogeus, pela cidade viva e pela cidade morta; o senhor levantou para mim o véu da misteriosa Isis e ressuscitou uma gigantesca civilização extinta. A história é sua, eu escrevi o romance; apenas tive que reunir, com meu estilo, como usando um cimento de mosaico, as pedras preciosas que o senhor me trazia. Th. G." (GAUTIER, 1858, dedicatória, s.p., tradução nossa). Disponível em: http://catalogue.bnf.fr/ark:/12148/cb30490246s. Acesso em 4 de novembro 2014.

9 "Um túmulo que não terá sido violado nem pelos reis pastores, nem pelos medos de Cambises, nem os gregos, nem os romanos, nem os árabes, e que nos entrega suas riquezas intocadas e seu mistério virgem [...]. ». (GAUTIER, 1858, p. 2, tradução nossa).

10 "Uma mão invisível havia invertido a ampulheta da eternidade, e os séculos de areia, escorrendo grão por grão como as horas na solidão e na noite, recomeçavam a cair.". (GAUTIER, 1858, p. 35-36, tradução nossa).
} 
o movimento mesmo da leitura que permite ao leitor tornar-se um viajante do tempo e penetrar em outros espaços-tempos. A distância de séculos e de culturas tão distantes e díspares produz, mais uma vez, pela mão de Gautier que vira a "ampulheta da eternidade", a narrativa de um amor absoluto e impossível, sempre associado à beleza.

Lorde Evandale é um belo jovem, de uma beleza perfeita, pura mas fria, como uma efígie de cera: " [...] il portait partout avec lui [...] une beauté dont on ne pouvait rien dire, sinon qu'elle était trop parfaite pour un homme. En effet, sa tête pure, mais froide, semblait une copie en cire de la tête de Méléagre ou de l'Antinoüs. ${ }^{11}$. 0 rapaz, a pós a leitura de sua história apaixona-se pela múmia que se encontra naquele túmulo. É descrita a beleza intacta da jovem morta, que vivera muitos séculos antes de Cristo:

Jamais statue grecque ou romaine n'offrit un galbe plus élégant; les caracteres particuliers de l'idéal égyptien donnaient même à ce beau corps si miraculeusement conservé une sveltesse et une légèreté que n'ont pas les arbres antiques. ${ }^{12}$

O egiptólogo alemão Rumphius, que acompanhara o jovem lorde em sua aventura arqueológica, depois de três anos de estudos, finalmente, decifra a história de Tahoser, nos papiros que haviam encontrado. 0 relato do alemão, romance da múmia, é uma narrativa dentro da narrativa (mise-en-abyme), como a múmia em seu sarcófago, relato que vem justificar o título do romance. Esta estratégia narrativa, a cena de uma simples transcrição de um relato que foi encontrado, apaga a presença do autor e confere à narrativa,

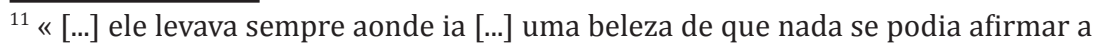
não ser que era perfeita demais para um homem. Com efeito, sua cabeça pura, mas fria, parecia uma cópia de cera da cabeça de Meléagro ou de Antínoo. » (GAUTIER, 1858, p. 3-4, tradução nossa).

12 « Jamais estátua grega ou romana apresentou curvas mais elegantes; e até mesmo os traços específicos do ideal egípcio conferiam a este belo corpo, tão milagrosamente conservado, uma finura e uma leveza que não possuem as árvores antigas." (GAUTIER, 1858, p. 55, tradução nossa).
} 
para o leitor de seu tempo, uma legitimidade de documento, tal como o define Jacques Le Goff (1924, p.526-527) :

0 documento que, para a escola positivista do fim do século XIX, será o fundamento do fato histórico, ainda que resulte da escolha, de uma decisão do historiador, parece apresentar-se por si mesmo como prova histórica. A sua objetividade parece opor-se à intencionalidade do monumento. Além do mais, afirma-se essencialmente como um testemunho escrito.

Tahoser fora enterrada como rainha do Egito, no vale dos Reis e não no vale das Rainhas, mais precisamente no túmulo que havia sido preparado para o Faraó Ramsés, aquele que teria sido engolido pelo Mar Vermelho, quando corria ao encalço de Moisés. Este episódio bíblico também é narrado por Gautier, no romance, de que constitui a última parte. A história tecida de amores impossíveis, do Faraó Ahmosis por Tahoser, e de Tahoser por um jovem judeu, Poëri, serve de pretexto para o talento descritivo do autor. Este nos transporta para as cenas que descreve, por sua qualidade plástica. E como quem não quer nada, aqui e ali, Gautier insere críticas à França de seu tempo e aos europeus civilizados. A sofisticação dos ritos fúnebres do antigo Egito serve de pretexto para uma crítica bem humorada à França contemporânea:

Quelle touchante coutume, dit le docteur Rumphius, enthousiasmé à la vue de ces trésors, d'ensevelir avec une jeune femme tout son coquet arsenal de toilette ! [...] à côté des Egyptiens, nous sommes vraiment des barbares; emportés par une vie brutale, nous n'avons plus le sens délicat de la mort. [...]

- Peut-être, répondit lord Evandale tout pensif, notre civilisation, que nous croyons culminante, n'est-elle qu'une décadence profonde, n'ayant plus même le souvenir historique des gigantesques sociétés disparues. Nous sommes stupidement fiers de quelques ingénieux mécanismes récemment inventés, et nous ne pensons pas aux colossales splendeurs, aux énormités irréalisables pour 
tout autre peuple, de l'antique terre des Pharaons. Nous avons la vapeur ; mais la vapeur est moins forte que la pensée qui élevait ces pyramides [....]. ${ }^{13}$

Em um constante exercício de seu estilo descritivo, Gautier nos leva a contemplar o Nilo, a cidade de Tebas (com os templos de Luxor e Karnac), a entrada triunfal do faraó, que retorna vitorioso de combates, os músicos e seus instrumentos, o esplendor dos palácios, com seus rituais, grandes pinturas de história. E em écfrasis de pequenas cenas de gênero, os humildes casebres e os costumes dos homens e das mulheres do povo. Ao descrever uma das salas do palácio do faraó, Gautier projeta em suas paredes uma imagem que ele chama de "desfile etnográfico", na qual vemos representantes de diferentes etnias; e neste desfile, o europeu vem por último e é « o mais selvagem de todos » (GAUTIER, 1858, p. 246-247).

Ao concluir o romance, o pudor de Gautier quanto a qualquer expressão sentimental leva-o a brincar com os clichês referentes a tipos nacionais, que caracterizam a literatura de consumo no século XIX, mencionando a excentricidade dos ingleses; o jovem lorde apaixonado pela bela múmia, por toda a eternidade, "retrospectivamente", jamais se casou. E o narrador comenta filosoficamente: "Il y a pourtant des folies anglaises moins motivées que celle-là".14

\footnotetext{
13 "Que costume tocante, disse o doutor Rumphius, entusiasmado ao ver esses tesouros, aquele de enterrar com uma jovem todo seu elegante arsenal de toalete! [...] comparados aos egípcios, somos realmente bárbaros; arrastados por uma vida brutal, perdemos o delicado sentido da morte. [...] - Talvez, respondeu Lorde Evandale profundamente pensativo, nossa civilização, que pensamos ser culminante, seja apenas uma decadência profunda, não tendo nem conservado a lembrança histórica das gigantescas sociedades que desapareceram. Temos um orgulho estúpido de alguns mecanismos engenhosos recentemente inventados e não lembramos os colossais esplendores, cuja enormidade é irrealizável para qualquer outro povo. Temos o vapor; mas o vapor é menos forte do que o pensamento que erguia estas pirâmides." (GAUTIER, 1858, p. 50-51, tradução nossa).

14 "Contudo há loucuras inglesas menos motivadas do que esta." (GAUTIER, 1858, p. 302, tradução nossa).
} 
Enquanto Gautier e escreve e publica seu romance, o canal de Suez está sendo projetado. 0 Egito, mais do que nunca está na moda, sobretudo graças à repercussão das primeiras descobertas arqueológicas de Auguste Mariette nas escavações de Sakkhara, que enriqueceram o acervo do Louvre com milhares de peças.

\section{Giuseppe Verdi e Aida}

A gênese de $A i d a$, seu processo de criação, ilustram de modo exemplar a circulação de ideais políticos, temas e estéticas, e a não menos intensa circulação de escritores, artistas e músicos, entre a Itália e a França, no século XIX. 0 próprio Verdi viajou inúmeras vezes a Paris, cidade em que viveu por longos períodos, sem ser objeto de curiosidade ou reprovação carola, com sua companheira, a soprano Giuseppina Strepponi (1815-1897). ${ }^{15}$

Várias óperas de Verdi retomam personagens e argumentos do repertório dramático francês do romantismo: Ernani (1844), inspirada pela peça homônima Hernani (1830), de Victor Hugo; o tema de Rigoletto (1851) provém de Le Roi s'amuse (0 rei se diverte, 1832), igualmente de autoria de Victor Hugo ${ }^{16}$, enquanto La Traviata (1853) retoma o argumento do romance de Alexandre Dumas filho, La Dame aux Camélias (A dama das Camélias,1848), que havia sido adaptado para o teatro em 1852. A Ópera de Paris tem laços estreitos com os gêneros dramáticos românticos, cujas intrigas inspiram os compositores (NAUGRETTE, 1981, p.84-85).

A recepção de Verdi, na França, em um primeiro momento, passa por grupos de franceses que apoiam a causa da unificação italiana e, por outro lado, por sua fama de ter renovado a tradição operística

\footnotetext{
15 Giuseppina Strepponi manteve, por muitos anos, uma relação com Giuseppe Verdi, que começa em 1846; eles só se casarão em 1859.

${ }^{16}$ A peça estreia dia 22 de novembro de 1832 e, logo após a primeira apresentação, foi proibida por imoralidade. Verdi modifica os títulos das personagens nobres, seus nomes, assim como a localização da ação, para fugir à censura (NAUGRETTE, 2011, p. nota a).
} 
apegada à fórmula do Bel Canto. Deve também ser mencionada a atuação de críticos folhetinistas, como o compositor e maestro Hector Berlioz (1803-1869), o maior crítico musical da França, e o próprio Théophile Gautier.

Gautier era considerado o maior crítico em seu tempo, na França, não apenas de artes plásticas, mas de artes dramáticas e espetáculos de dança, líricos e de ópera, em La Presse (1836-1855) e posteriormente no Moniteur Universel (1855-1868). As posições do escritor e do compositor, enquanto críticos de música, são bem contrastadas: Gautier é um entusiasta da ópera italiana, embora considere os libretos "em sua maioria incomprehensíveis ou estúpidos"17, enquanto Berlioz prefere a escola alemã de música ${ }^{18}$. Assim, Gautier acompanhou a trajetória de Giuseppe Verdi, de que sempre foi um defensor entusiasmado.

Com sua potência criadora e a visão da ópera como espetáculo em que se integram história, libretto, cantores e músicos, Verdi vai deixando de lado a fórmula de óperas em que a trama é um mero pretexto para criar momentos fortes que valorizem as áreas. Ele cria óperas que assumem um aspecto dramático, no qual a orquestra tem um grande protagonismo. Suas obras seduzem o exigente público parisiense e o imperador Napoléon III, a tal ponto que em 1853 lhe é encomendada uma ópera para a abertura da Exposição Universal

\footnotetext{
17 “[...] aucun ouvrage n'a complètement réussi aux Bouffes, à l'exception de Donizetti, qui, avec Rossini et Bellini, composent pour ainsi dire tout le répertoire. - La faute n'en est pas au directeur, qui a consciencieusement fait jouer à Paris tout ce qui avait réussi sur les scènes d'Italie. On doit en accuser un peu les compositeurs, et beaucoup les livrets, inintelligibles ou stupides pour la plupart, ce qui choque toujours vivement le public français. » "[...] obra alguma teve um real sucesso no teatro de Bouffes, excetuando-se Donizetti, o qual com Rossini e Bellini, compõe de certo modo todo o repertório. - Não é por culpa do diretor, que fez conscienciosamente representar em Paris tudo o que havia sido um sucesso nos palcos da Itália. Os responsáveis são, um pouco, os compositores e, muito, os libretos, os quais em sua maioria são incompreensíveis ou estúpidos." (La Presse, 30 de setembro de 1844, p. 2, tradução nossa).

18 Berlioz, polêmico e irônico, é muito mais crítico em relação à escola italiana de música, sobretudo desde sua estada na Itália, em 1831, após ter ganho o Prêmio de Roma, quando se decepciona com a situação decadente da música e dos músicos (BERLIOZ, 1991).
} 
de 1855. Verdi passa então três anos em Paris e compõe, com um libreto de Eugène Scribe (1791-1861) e Duveyrier (1803-1866), Les Vêpres siciliennes, que foi traduzido, meses depois por Caimi, para a Scala de Milão: I Vespri Siciliani (1856). A fama do compositor já fizera de sua obra um sucesso internacional, enquanto os encantos da ópera italiana chegam ao Egito.

O primeiro responsável pela gênese de Aida foi o sultão Khédive Ismail. ${ }^{19}$ Formado na admiração da cultura europeia, ao se tornar vice-rei do Egito, em 1763, em seu projeto de modernizar o país, ele assegura a realização do projeto de Ferdinand de Lesseps de abrir o canal de Suez, finalmente inaugurado em 17 de novembro de 1869. Ele foi, também, diretamente responsável pela construção da ópera do Cairo, para celebrar aquele acontecimento e indiretamente pelo fato de Verdi ter sido o compositor solicitado para compor uma ópera para sua inauguração.

O Khédive Ismail tinha o projeto de inaugurar o Canal de Suez com uma série de festividades solenes, para as quais convidara todos os soberanos da Europa. Estas festividades foram organizadas por Auguste Mariette, que já havia sido responsável pelo pavilhão do Egito na Exposição Universal de Londres, em 1862, e na Exposição Universal de 1867, em Paris. Arqueólogo de fama incontestável, naquela altura ele já não mais era um funcionário do Louvre, mas do governo egípcio; fora nomeado Inspetor Geral e Conservador dos Monumentos do Egito e era responsável por políticas de conservação e proteção aos vestígios do Egito antigo. ${ }^{20}$

O Khédive lhe encomenda, então, uma ópera egípcia que seria representada na inauguração do Grande Teatro do Cairo, construído por ocasião das festividades do Canal de Suez. O sultão, apaixonado por ópera, e que conhecia todo o repertório da ópera italiana, desejara dar ao Egito uma sala com padrões europeus e que apresentasse os melhores recursos de conforto e acústica,

\footnotetext{
${ }^{19} \mathrm{O}$ Egito fazia parte do império otomano; Khédive era o título honorífico que era concedido aos vice-reis do Egito entre 1867 e 1914.

${ }^{20}$ Com esta finalidade ele cria o Museu de Boulaq (1863-1889), cujo acervo hoje se encontra no Museu egípcio do Cairo, inaugurado em 1902.
} 
em seu tempo. Este teatro, que foi chamado de Ópera Khédival e que, infelizmente, foi destruído em um incêndio em 1971, deveria ser inaugurado com uma obra que celebrasse a antiga história do Egito. Para a trama de autoria de Mariette Pacha, de quem o Khédive exigira um enredo, o vice-rei exigiu também o maior compositor de óperas em seu tempo, Verdi. Esta é a origem de Aida. (ISON, 1999, p. 278).

No site oficial da Ópera do Cairo, há o registro da construção da Ópera Khédival e da gênese da ópera Aida, cujo ponto de partida, como já foi mencionado, teria sido um projeto do Khédive:

Par ailleurs et avant l'achèvement de la construction, il a cherché à présenter une ouvre qui traduit [sic] l'histoire de l'Egypte. Il a choisi une ancienne histoire égyptienne écrite par Mariette pacha et a demandé au poète italien Ghislanzoni de la transformer en pièce d'opéra et de [sic] son compatriote, le grand musicien Verdi, de composer sa musique. Par conséquent, cette combinaison impeccable a engendré au monde l'opéra d'Aida. [...] Et malgré les efforts effectués et la volonté de Khédive Ismail, l'opéra a été inauguré en novembre 1869, lors de la célébration de l'ouverture du Canal de Suez par un autre spectacle, c'était l'opéra de Rugolotto [sic] toujours composé par Verdi. ${ }^{21}$

0 maestro, de início, não aceitara o convite, recusa contornada por um hábil artifício do diretor da Ópera Cômica de Paris, Camille du Locle (1832-1903). Este lhe encaminha o argumento de Aida, sem nome de autor, acompanhado por uma carta de Mariette, a qual traz em seu post-scriptum a seguinte frase: "si le signor Verdi

\footnotetext{
${ }^{21}$ « Por outro lado e antes de terminar a construção, ele procurou apresentar uma obra que traduzisse a história do Egito. Ele escolheu uma antiga história egípcia, escrita por Mariette Pacha e pediu ao poeta italiano Ghislanzoni que a transformasse em libreto e que seu compatriota, o grande músico Verdi, compusesse a música. Por conseguinte, esta impecável combinação gerou para o mundo a ópera Aida [...] E apesar dos esforços empenhados e da vontade de Khédive Ismail, a ópera foi inaugurada em novembro de 1869, por ocasião da abertura do Canal de Suez por outro espetáculo, a ópera Rigoletto, igualmente composta por Verdi." (Disponível em http://www.cairoopera.org/history.php. Acesso em 15 de agosto de 2013, tradução nossa)
} 
n'accepte pas, Son Altesse vous prie de frapper à une autre porte... Elle pense à Gounod et aussi à Wagner."22

Não é bem assim que a história é contada na biografia de Verdi, de autoria de seu contemporâneo Pougin (1886). 0 maestro teria sido seduzido pelo convite e aceita o régio contrato:

Verdi fut séduit tout d'abord: d'une part, par la grandeur de la donnée générale; de l'autre, par l'idée première de la scène du jugement, à laquelle on doit le tableau étrange et puissamment dramatique qui forme le dénouement. Il comprit tout le parti qu'on pouvait tirer musicalement d'un tel sujet, et n'hésita pas à l'accepter. ${ }^{23}$

Repugnara-lhe a encomenda de um vice-rei déspota? Penso que não, ele já atendera ao convite de Napoleão III, e aceitara o convite do Czar, em 1862, para uma apresentação em São Petersburgo da ópera La forza del destino, além disso, o Khédive era um tirano progressista: almejava libertar o Egito da Sublime Porta - a dominação turca - e, além disso, era um grande amador de ópera. O mais provável é que Verdi temesse a travessia por mar (POUGIN, 1886, p. 221). Foi então feito um arranjo para a dupla estreia da ópera, uma no Cairo e a outra em Milão, no La Scala, logo após aquela do Cairo. A primeira récita ocorre em 24 de dezembro de 1871 e a segunda, seis semanas depois, em 7 de fevereiro de 1872 (POUGIN, 1886, p. 232).

O sucesso de Aida foi imenso e imediato, tanto no Cairo quanto em Milão. Depois em seu giro d'Italia e nas capitais europeias, obtém um estrondoso sucesso.

\footnotetext{
22 "caso o signor Verdi não aceite [o convite], sua alteza lhe pede que o Senhor bata em uma outra porta... Ela está pensando em Gounod e também em Wagner." (ISON, 1999, p. 279, tradução nossa).

23 "Verdi foi seduzido logo: por um lado, pela grandeza geral da proposta, e, por outro lado, pela ideia primeira do julgamento, à qual se deve o quadro estranho e poderosamente dramático que forma o desenlace. Ele compreendeu todo o partido que ele poderia tirar, musicalmente, de um tema como esse e não hesitou em aceitar." (POUGIN, 1886, p. 217, tradução nossa).
} 
Le soir même de la première représentation, après le deuxième acte, une députation d'artistes s'approcha de Verdi et lui offrit un superbe sceptre en ivoire orné d'une étoile en diamants, semblable à celui que porte le roi d'Egypte dans l'opéra; sur ce sceptre était tracé en rubis le nom d'Aida, tandis que celui de Verdi se détachait en pierres précieuses sur une branche de laurier. ${ }^{24}$

Aida é uma ópera bastante complexa, para alguns é a última das grandes óperas; sua criação envolveu, além do compositor, vários colaboradores, a começar pelo autor do enredo, Auguste Mariette. 0 argumento de Aida teria sido desenvolvido, em prosa, cena por cena, por Camille du Locle, que criou os diálogos, em Bussetto, sob a atenta supervisão de Verdi: "L'idée du finale du dernier acte, avec ses deux scènes superposées, lui appartient particulièrement.". ${ }^{25}$

A tradução em versos italianos é de autoria do poeta italiano Antonio Ghislanzoni (1824-1893). Alguns anos depois, os versos foram traduzidos para o francês, para a estreia de Aida na Ópera de Paris. Du Locle, em carta enviada ao jornal L'Italia, de Roma, em 1880 , por causa de uma polêmica, na imprensa italiana, envolvendo autorias esclarece a participação de cada um (POUGIN, 1886, p. 219 220). Encerrada a composição do libretto, Verdi criou a partitura.

Para a composição musical, em um primeiro momento, Verdi pensa em reconstituir a música do Egito dos faraós e informa-se junto a Mariette sobre os instrumentos egípcios antigos e as danças sagradas; apesar das descrições fornecidas por Mariette, face às lacunas de documentação, Verdi deixa de lado este projeto e tenta criar uma música "à moda egípcia", com temas turcos que são destinados a produzir uma cor local. Ele encomenda, então, a um

\footnotetext{
24 "Já na noite de estreia, depois do segundo ato, uma delegação de artistas aproximou-se de Verdi e ofereceu-lhe um soberbo cetro de marfim, adornado com uma estrela de diamantes, semelhante àquele do rei do Egito na ópera; no cetro havia sido incrustado em rubis o nome de Aida, enquanto o nome de Verdi se destacava com pedras preciosas em um ramo de louro." (POUGIN, 1886, p. 232, tradução nossa).

25 "A ideia do finale do último ato, com suas duas cenas superpostas, lhe pertence particularmente." (POUGIN, 1886, p. 219, tradução nossa).
} 
artesão de Milão réplicas das trombetas do Egito, que, conforme narra Plutarco, "lembravam o grito dos burros" (ISON, 1999, p. 280).

A ópera envolveu grandes dificuldades técnicas para a construção de cenários, produção de objetos de cena, armas e joias, assim como para a confecção de figurinos, todos desenhados por Mariette, o qual exigiu, nos mínimos detalhes, a máxima fidelidade histórica. Para inspirar-se, o arqueólogo se recolhera no templo de Ísis, na ilha de Philae, no Egito. Acessórios e maquinaria foram confeccionados no Cairo, cenários e figurinos, em Paris. Como a História atravessa certos sonhos, com a guerra franco-prussiana de 1870, cenários e figurinos ficaram presos na capital de França sitiada e a ópera do Cairo, afinal, foi inaugurada, como já foi mencionado, com outra composição de Verdi, a ópera Rigoletto.

Como em Nabucco (1842), reencontramos, em Aida, a solenidade dos sacerdotes, o coro das massas, a dramaticidade do grupo de escravos. A minissérie da R.A.I, Giuseppe Verdi, sua vida, sua obra, aponta uma novidade: a sensualidade da ópera (GIUSEPPE VERDI, 1982). Certamente um ingrediente indispensável do imaginário romântico de oriente, que confunde escravas e concubinas, danças rituais e a beleza de corpos nus, Egito antigo e haréns muçulmanos.

A trágica paixão que une Aida, uma princesa da Etiópia, escrava no Egito, a um general egípcio, Radamès, é um topos dramático muito conhecido. A personagem dividida entre a lealdade a seu pai e a paixão amorosa por Radamès reatualiza o drama de Chimène, no El Cid (1637) de Corneille (1606-1684), dividida entre o dever para com a memória de Don Gomez e o amor por Don Rodrigue. Da mesma peça, reconhecemos o orgulho e o amor frustrados da antagonista de Aida, a filha do Faraó, apaixonada por Radamès, que reedita a personagem da Infanta espanhola. 0 cruel destino dos amantes, Aida condenada a ser enterrada viva e Radamès que a segue para compartilhar seu castigo, é o castigo que Creonte reservara a Antígona, na peça homônima (cerca de 442 a.C) de Sófocles. 


\section{0 triunfo do faraó}

No contexto deste ensaio, não caberia um cotejo ponto por ponto das sequências do romance com as cenas da ópera, nem é nosso objetivo um estudo comparativo de tramas. Na perspectiva proposta, de construção de imaginários de impérios, em uma ambientação de um Egito oriental, destaca-se o triunfo do faraó, presente nas duas obras. A representação do poder e do esplendor político, fundamentado em um poderio bélico, no Romance da múmia e em Aida, está fundamentalmente concentrada na figura do faraó, que retorna vitorioso de suas batalhas e nas cenas que compõem o desfile de guerreiros, em que ressaltamos a presença dos sacerdotes.

$\mathrm{Na}$ ópera, os diferentes grupos que ocupam sucessivamente o palco, em um triunfo que é mais romano do que egípcio, desfilam em uma ordem muito próxima daquela que lemos no Romance da múmia. Na obra de Gautier, primeiramente, é descrita a multidão que espera o retorno do rei. Abrindo o desfile, os sacerdotes, seguidos por soldados e altas personalidades. Contrastando com esse grupo, temos mulheres semidespidas, com os filhos pequenos no colo, extremamente pobres, e ainda, belas mulheres abastadas, acompanhadas por três ou quatro criadas. Tahoser desloca-se, junto com a multidão, para ver a chegada do faraó, que é precedida por um rumor extraordinário, provocado por instrumentos, carros de guerra, e depois a infantaria, com o trepidar dos passos dos combatentes. Abrem o desfile militar os músicos, seguidos pelos aliados e por último, temos a descrição do botim:

L'avant-garde des musiciens s'arrêta quelques instants; des colléges [sic] de prêtres, des députations des principaux habitants de Thèbes [...] se rangèrent en haie dans les poses du respect le plus profond, de manière à laisser le passage libre au cortège.

La musique, qui, a elle seule, eût pu former une petite armée, se composait de tambours, de tambourins, de trompettes et de sistres. 
Le premier peloton passa, sonnant une retentissante fanfarre de triomphe dans ses courts clairons de cuivre brillants comme de l'or. ${ }^{26}$

Em Aida (II, 2), vemos em primeiro lugar o faraó, os sacerdotes, seguidos pelos feitores armados com chicotes que conduzem os escravos; há um número de dança e depois o desfile de tropas, precedidas pela fanfarra: a infantaria, carros de guerras, carroças carregando troféus e estátuas de divindades, a cavalaria, os prisioneiros de guerra.

Assim como no romance de Gautier, as trombetas assumem um relevo especial, na Marcia trionfale (Marcha triunfal, II, 2), também conhecida como marcha das trombetas; tratase da adaptação de trombetas encomendadas por Verdi, que foi chamada de trombeta tebana exatamente a partir da representação de $A i d a$, e que hoje também é chamada de trombeta tebana (OPHICLÉDIDE 2009).

Associam-se, aqui, os dois fortes elementos musicais e dramáticos da formação juvenil de Verdi: a música sacra que acompanha rituais religiosos e as marchas tocadas por bandas militares. Estas operam como metonímias, respectivamente, da Igreja e do Estado. Sacerdotes e governantes que se confundem com chefes guerreiros representam, na obra de Verdi, aqui, duas instituições autoritárias, as quais, juntamente com a família burguesa e seus valores, sacrificam as grandes paixões.

\section{Considerações finais}

0 romance e a ópera, em uma abordagem meramente

\footnotetext{
26 “A vanguarda dos músicos parou por alguns instantes; colégios de sacerdotes, representantes dos principais habitantes de Tebas [...] abriram alas, na atitude do mais profundo respeito de modo a deixar passar o cortejo. A música, que sozinha poderia formar um pequeno exército, compunha-se de tambores, tamborins, trombetas e sistros. O primeiro pelotão passou, tocando uma retumbante fanfarra de triunfo em seus curtos clarins reluzentes como ouro." (GAUTIER, 1858, p. 102, tradução nossa).
} 
temática, parecem não trazer nenhum registro do contexto histórico de sua criação. E as imagens mesmas que projetam do antigo Egito são imagens que nos habituamos a chamar de românticas, aquelas que encantaram, e continuam encantando tantos viajantes ocidentais. Esse Egito antigo, hoje de turismo de massa, das pirâmides, da esfinge, dos túmulos de faraós e dos templos ao longo do rio Nilo, como aquele de Luxor, é um Egito que os arqueólogos do longo século XIX descobriram literalmente, desencavando-o da areia, e que se confunde, para nós, com imaginários de que já fazem parte estes mesmos viajantes, reais ou saídos da ficção, como as personagens de Morte sobre o Nilo (1937), de Agatha Christie.

Ao examinarmos de perto a cena enunciativa ${ }^{27}$ das duas obras, vemos que, embora aparentemente esteja distante no espaço e no tempo da Europa do século XIX, o antigo Egito dos faraós assume, na tradição literária, tanto aquela das narrativas orientalistas quanto a dos preceitos aristotélicos referentes à tragédia, um valor alegórico, de encenação de espaços de poder e crítica política. Essa crítica ultrapassa uma postura de oposição ao Segundo Império francês, no que se refere a Théophile Gautier, que detestava notoriamente qualquer envolvimento político, e ainda não se confunde com o traço de resistência ao Império austríaco, na ópera de Giuseppe Verdi. Talvez, entretanto, com um impacto que vem em parte pelo fato de integrarem obras que, por sua permanência no cânone, recebemos hoje cortadas de um contexto histórico e político direto, essas imagens de Egito permaneçam investidas, em nossos dias, do potencial de desvelar a crueldade dos poderes

\footnotetext{
${ }^{27}$ Cena enunciativa ou cena de enunciação, noção vinculada à análise do discurso, formulada por Dominique Maingueneau: "[...] en parlant de 'scène d'énonciation', on met l'accent sur le fait que l'énonciation advient dans un espace institué, défini par le genre de discours, mais aussi sur la dimension constructive du discours, qui se 'met en scène', instaure son propre espace d'énonciation. " - " [...] ao nos referirmos a 'cena de enunciação', acentuamos o fato de que a enunciação ocorre em um espaço instituído, definido pelo gênero do discurso, mas também pela dimensão construtiva do discurso, que se 'encena', instaura seu próprio espaço de enunciação." (CHARAUDEAU \& MAINGUENEAU, 2002, s.v. Scène d'énonciation, p.515, tradução nossa, destaques do autor).
} 
arbitrários de todos os regimes autoritários, de que é feita a alegoria construída a partir do imenso poderio dos faraós.

\section{REFERÊNCIAS BIBLIOGRÁFICAS}

BERLIOZ, H. Mémoires. Paris : Flammarion, 1991.

BONNEWITZ, P. Pierre Bourdieu ; vie, oeuvre, concepts. Paris : Ellipses, 2002.

CHARAUDEAU, P. \& MAINGUENEAU, D. Dictionnaire d'analyse du discours. Paris : Seuil, 2002.

DU CAMP, M. Égypte, Nubie, Palestine et Syrie : dessins photographiques recueillis pendant les années 1849, 1850 et 1851, accompagnés d'un texte explicatif et précédés d'une introduction par Maxime Du Camp, chargé d'une mission archéologique en Orient par le ministère de l'Instruction publique. Paris : Gide et Baudry, 1852.

Disponível em http://gallica.bnf.fr/ark:/12148/ btv1b86260711.r=.langPT. Acesso em 31 de agosto de 2013.

FEYDEAU, E. Histoire des usages funèbres etdes sépultures des peuples anciens. Paris : GIDE \& BAUDRY, 1856.

Disponível em http://books.google.com.br/book. Acesso em 21 de novembro 2014.

GAUTIER, T. Feuilleton de La Presse. La Presse, Paris, 30 de setembro de 1844, p. 1-2. Disponível em http://gallica.bnf.fr/ark:/12148/bpt6k429717x.

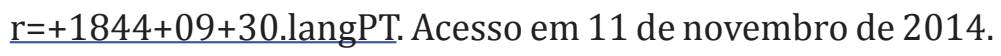


GAUTIER, T. Le Roman de la momie. Paris : Hachette, 1858.

Disponível em http://catalogue.bnf.fr/ark:/12148/ cb30490246s. Acesso em 4 de novembro 2014.

Emaux et camées, avec une iconographie rassemblée et commentée par Madeleine Cottin. Paris : Lettres Modernes Minard, 1968.

. Contes et récits fantastiques. Paris : Librairie Générale Française, 1990.

. Un repas au désert de l'Egypte. Disponível em http://www.logoslibrary.eu/document.php. Acesso em 21 de novembro 2014.

GIUSEPPE VERDI; Sua vida, sua obra. (La vita de Verdi). DVD. Itália, França, Alemanha: RAI \& TRADE, 1982.

ISON, C. Le Tourneur d'. Mariette Pacha ou le rêve égyptien. Paris : Plon, 1999.

LE GOFF, J. História e memória. Trad. Bernardo Leitão [et al.]. Campinas, SP: Editora da Unicamp, 2003.

LOVENJOUL, Ch. Histoire des oeuvres de Théophile Gautier. Tome deuxième. Genève: Slatkine, 1968. (Facsímile da edição de Paris, 1887). Disponível em gallica.bnf.fr/ ark:/12148/bpt6k8840n. Acesso em 05 de novembro 2014.

NAUGRETTE, Fl. Le théâtre romantique; histoire, écriture, mise en scène. Paris : Seuil, 2001. 
POUGIN, A. Verdi ; Histoire anecdoctique de sa vie et de ses oeuvres. Paris: Calmann Lévy, 1886.

Disponível em http//bnffrr / Bibliothèque nationale de France. Acesso em 31 de agosto 2013.

SAÏD, E. Orientalismo; o Oriente como invenção do Ocidente. Trad. Rosaura Eichenberg. Coleção Companhia de Bolso. São Paulo :Companhia das Letras, 2007.

VERDI, G. Aida. Chorus, ballet and orchestra of the National Theatre Brno; Ernst Mäzendorfer. DVD. República Tcheca Brno: Euro Arts \& Video Brokers, 2009.

Sites:

http://www.cairoopera.org/history.php, consultado em 15 de agosto de 2013.

http://www.ophicleide.fr/fr/133250881820376-unetrompette-un-peu-particuliere-.html\#.VHRl_81NeTc, consultado em 25 de novembro de 2014.

1ritiques européens, M. Ernest ébt eur FilippFilippi, de la Perseverza, 
